ing in conjunction with the Radio Spectroscopy Group during Easter at the University of Nottingham on the subject of solid-state amplifiers, and with the Low Temperature Group (November 15) to discuss electronic devices for helium temperatures.

The accounts presented in the annual report show that the amalgamation cost the new body and its predecessors $£ 1,420$, of which about half was for legal expenses. On July 13, 1960, at its first meeting, the Council of the new organization established "The Physics Trust Fund", the object of which is to finance the educational and scientific work of the Institute and Society, including the production and publication of its scientific periodicals and its meet- ings. The fund has been recognized as a charity by the Commissioners of Inland Revenue although the parent body has not. To finance its increasing activities, the Institute and Society launched an appeal for $£ 140,000$, and by the end of 1960 the total in gifts and covenanted promises received amounted

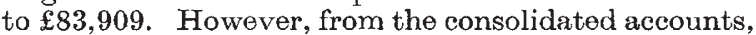
which aro included in order to give a simple general picture of the financial position at December 31, 1960 , and of the year's working, it is clear that the reserves available to the Council are still in need of substantial increase if the programme planned for the expansion and improvement of the activities of the Institute and Society is to be maintained.

S. Weintroub

\title{
BRITISH RESEARCH ON THE HIGH ATMOSPHERE
}

\begin{abstract}
r. $\mathrm{TE}$ Meteorological Office programme of research on the high atmosphere is summarized by Dr. R. Frith in the Meteorological Office report for the year ending December 31, 1960*. The object of the research is to examine the variations of meteorological parameters in the high atmosphere and to attempt to link them with what takes place at lower levels. 'The problem is being attacked in several ways. First, the occurrence of strong very turbulent winds at $75-110 \mathrm{~km}$. has been disclosed from the study of ionized trails left by meteors. The large number of observations, mostly obtained by a team at the University of Manchoster, is being examined systematically. Secondly, it is hoped to make routine rocket soundings up to at least sixty kilometres by the end of 1962. The rockets will release a temperature sonde at apogee and the descent will be controlled by a special type of parachute, which will also act as a radar target, so enabling the winds to be measured. It is hoped to use larger rockets to eject 'window', or a sphere, so as to obtain wind measurements at higher levels during 1963. The grenade method, whereby gronades are ejected from a rocket and exploded at intervals, may also be tried in order to obtrain mean winds and temperatures between the levels of suecessive explosions.
\end{abstract}

* Annual Report on the Meteorological Office for the year January 1 to December 31, 1960. Pp. 67+4 plates. (M.0. 710.) (London: H.M. Stationery Offiee, 1961.) $4 s$. 6d. net.
A third research method is already in operation experimentally. It is possible to deduce the air density at a given level by measuring the light scattered at that level from a powerful searchlight beam, provided the air at and above thirty kilometres, at which height the density is known from radiosonde determinations, is 'clean'. Experiments over a $40 \mathrm{~km}$. base-line across Cardigan Bay have revealed unexpectedly large scattering above 60 $\mathrm{km}$. This may be due to dust, but is so far unexplained.

Fourthly, the Meteorological Office is at present building and testing instruments for use on the second British satellite, to be put into orbit in 1963 by an American Scout rocket. The aim is to measure the vertical distribution of ozone, using sensors which respond only to radiation in one of the ozone absorption bands. Mostly, a satellite is either in complete sunlight or complete darlness, and no measurements ean then be obtained. Since the satellite will be in orbit beyond the ozone layer it will see the Sun for about a minute twice on each orbit, through varying thicknesses of atmosphere. It is in these $2 \mathrm{~min}$. that useful measurements can be obtained. It is hoped to obtain information, particularly below $40 \mathrm{~km}$., where the life of ozone molecules is long enough to enable ozone to be used as a meteorological tracer, thereby providing information on the general circulation and vertical motion in this little-known region.

\section{UPPER ATMOSPHERE RESEARCH IN AUSTRALIA}

\begin{abstract}
A S a supplement to the thirteenth annual report A of the Commonwealth Scientific and Industrial Research Organization, Australia (see Nature, 192, $712 ; 1961)$, the report of the Upper Atmosphere Section for the year ended June 30, 1961, has recently been published*. This Section, under Dr. D. F. Martyn, with headquarters at Harben Vale, Camden, New South Wales, is concerned with investigation of the atmosphere above about $50 \mathrm{~km}$. by various experimental methods involving radio and optical techniques. The small changes of the Earth's mag. netic field due to electric currents in the ionosphere

* Commonwealth of Australia. Commonwenlth Seientific and Industrial Research Organization. Upper Atmosphere Section Annual Canberra, Adelaide, Camden: C.S.I.R.O., 1961.)
\end{abstract}

have also been under investigation. During the past year the programme of work has been increasingly directed towards the measurement of phenomena of the upper atmosphere by the use of rockets and satellites.

Several field stations have been equipped with rotating-loop direction finders for locating the sources of low-frequency atmospheric noise, the intensity of which is also measured over a frequency-range of $1-40 \mathrm{kc} . / \mathrm{s}$., special attention being given to the background noise in the band 4-6 kc./s.

On moonless nights the sky is still faintly illuminated, partly by airglow caused by the self-luminescence of the gases in the upper atmosphere. The strongest spectral lines in the airglow are the green and red lines emitted by atomic oxygen at wave- 
lengths of 5577 and $6300 \AA$., respectively. Photometric apparatus installed for use during the International Geophysical Year has been improved, and observations on these lines have been resumed. While the telescope used for this work normally points to the south at a zenith angle of $80^{\circ}$, it can quickly be changed to an all-sky survey when required to observe aurora.

Observations of geomagnetic micropulsations have been made during the year at Camdon and Adelaide, by means of a large horizontal loop of wire buried in the ground and connected to a galvanometer-photocell amplifier. The pulsations are recorded on paper charts or on magnetic tapes, the latter having the advantage that they may be replayed at such a speed that the oscillations are in the audio-frequency range which facilitates their analysis. The most common frequencies of these pulsations observed at Hobart, Adelaide and Townsville were 1.3, 2.5 and $3 \mathrm{c} . / \mathrm{min}$., respectively. They exist for periods which show a diurnal variation; at Adelaide, for example, the period varies smoothly from about 15 sec. at $0600 \mathrm{hr}$. to 24 sec. at midday.

During magnetically disturbed periods, it has been found that the frequency of the pulsations may sweep over a range of 1-32 c./min., at a rate of approximately $1 \mathrm{c} . / \mathrm{min} . / \mathrm{min}$. Although swept frequency micropulsations have previously been observed in other countries, these have been at frequencies of about $2 \mathrm{c} . / \mathrm{s}$. The low-frequency events recorded above do not appear to have been noticed before.

\section{THE BRITISH BOOT, SHOE AND ALLIED TRADES RESEARCH ASSOCIATION}

$\mathrm{T}$ WELVE years ago Nature published an article on the British Boot, Shoe and Allied Trades Research Association (SATRA) (Nature, 164, 871; 1949), on the occasion of the opening of new labora. tories at Satra House, Kettering, by H.R.H. Duke of Gloucester. The Association was then in the throes of its post-war re-organization and the article proudly proclaimed "to-day the whole of the shoe industry of Great Britain is connected with the Research Association either in full membership or affiliation".

The intervening twelve years have been a period of vigorous activity in various sections of the Association's programme and the grip of the Association on its industry has strengthened; the usefulness of the Association and the practical application of its recommendations have interpenetrated the whole industry so that to-day it can be asserted with confidence that this Research Association is thoroughly integrated with its industry and accepted without question as essential to the industry's well-being in this scientific era. The present article follows a recent visit to the Association made by $\mathrm{Mr}$. Denzil Freeth, Parliamentary Secretary to the Minister for Science, who was much impressed by all that he saw.

The research association concept as understood at Satra is that a research association should mature to become the spearhead of its industry's drive into the future, to give the lead and to be an implement for the enhancement of the industry's progressiveness. It must therefore itself be an exemplar of progressiveness and any activity which is definitely conducive to progressiveness in the industry comes reasonably within the research association's scope.

For the attainment of this concept experience shows that, at any rate for small-firm craft-based industry, the research association must be a tripartite organization with a kind of equivalence of strength between the parts, which are: the industry, the public (Government), and the staff. All these must be present in strength; without the industry the association would obviously be a Government research station; without the Government it would be just a trade association; with both industry and Government the staff can be strong in purpose, cerving a cause, and gaining confidence and stature in their national status. A research association is thus a stable tripod with three strong legs, and any serious weakening of any one of the legs means departure from the perfect research association as here conconceived.

Policy and programmes of research are of course in consonance with this structure and at Satra they embrace practical work on factory productivities, operational research, ergonomics; work for the improvements of the product, consumer satisfaction, and for the public good; basic research in the science of materials and the fringe sciences of bio-mechanics and bio-physics. All parts of the programme are planned to afford scope to research workers of highest calibre.

Satra's achievements can conveniently be grouped into three sections: materials, manufacture and the product.

The shoe-manufacturing industry buys its materials and components to a total of something of the order of $£ 100,000,000$ per year. The Research Association's contribution is to minimize waste in this expenditure by establishing quality targets, grades and specifications to guide the supplying industries in their development work and to guide also the shoe factory personnel in their purchasing appropriately to their product. The supply industries total approximately one-half of the Research Association's membership and they work very closely indeed with Satra.

The past twelve years have witnessed an enormous expansion in variety in shoe materials concurrently with the growth of the chemical and synthetic industries, and the smoothness with which the new materials, and the new shoe-making methods associated with them, have been absorbed into the industry without the wasteful losses of old-time trial-anderror methods is legitimately to be regarded as one of this Association's great achievements.

The Association has had conspicuous success in its contribution to the efficiency of shoe factories and management techniques. Twelve years ago the Association had initiated inter-firm comparison work on productivities; later, the work expanded under the heading 'ergonomics' to include the various aspects of work study, operative training, production planning and work loading and many case-studies of factory re-organization. There have also been very important contributions from physics research with 